\title{
Effects of Manganese on Highly Donor-Doped Barium Titanate Ceramics with Resistivity of Positive Temperature Coefficient
}

\author{
Jianqiao LIU ${ }^{1}$, Guohua JIN ${ }^{1}$, Yuzhen CHEN $^{2}$, Zhaoxia ZHAI ${ }^{1 *}$ \\ ${ }^{1}$ College of Information Science and Technology, Dalian Maritime University, Dalian 116026, Liaoning, China P.R. \\ ${ }^{2}$ Department of Material Science and Engineering, Dalian Maritime University, Dalian, 116026, Liaoning, China P.R. \\ crossref http://dx.doi.org/10.5755/j01.ms.26.4.23523
}

Received 04 June 2019; accepted 07 October 2019

\begin{abstract}
Highly donor-doped ceramics with composition of $\mathrm{Ba}_{0.984} \mathrm{Y}_{0.016} \mathrm{TiO}_{3}$ were prepared for thermistors with positive temperature coefficient of resistivity (PTCR) via a route of solid reaction, reducing sintering and aerial oxidation. The effects of Mn additive were investigated on the ceramic characteristics of composition, morphology and electrical properties. The $\mathrm{Mn}$ incorporation affected little on ceramic composition but resulted in an obvious change in ceramic morphology, which illustrated the average grain size of 1.16, 1.65 and $1.01 \mu \mathrm{m}$ for Mn addition amount of $0,0.0005$ and 0.0010 , respectively. The grain growth, together with the Mn additive, influenced the electrical properties of room temperature resistivity, PTCR jump, donor and acceptor densities as well as the depletion layer width.

Keywords: barium titanate, PTCR, electrical properties, manganese, thermistor.
\end{abstract}

\section{INTRODUCTION}

Barium titanate $\left(\mathrm{BaTiO}_{3}\right)$ is a typical semiconductor, which has many successful applications due to its characteristics of dielectricity $[1,2]$, piezoelectricity $[3,4]$, ferroelectricity [5,6] and nonlinear optical properties [7]. Polycrystalline $\mathrm{BaTiO}_{3}$ ceramics were found to have positive temperature coefficient of resistivity (PTCR) [8] and they were soon put into the fabrication of thermistors [9-12]. The effect of PTCR was resulted from the decrease of dielectric constant when the operating temperature was above the Curie point [13]. However, it was found that the conventional $\mathrm{BaTiO}_{3}$-based ceramics were not competent enough for practical applications. In order to meet the demands of electronic devices with high performances, the $\mathrm{BaTiO}_{3}$ ceramics were expected to have not only a low room temperature resistivity but also a large PTCR jump. Thus, several ways were developed to enhance the ceramic properties and one of them was incorporation of foreign elements [14-19]. For example, $\mathrm{Ca}$ incorporation would inhibit the grain growth [20] and Sr was used to shift the Curie point [21-23]. The elements of Sm [24], Y [25, 26] and La [27] were doped as donors to substitute $\mathrm{Ba}$ sites. The ionization of donors provided semiconductive nature of ceramics and their amount also made impacts on the ceramic characteristics [28]. The acceptors on the grain surface included Mn additive [29] and $\mathrm{Ti}$ vacancies in some cases $[30,31]$, except for the adsorbed oxygen $[15,32]$. The acceptors could seize the electrons in the grain, which were produced from the ionized donors, leaving a depletion layer at the grain boundary [33]. Thus, the PTCR was concluded as an effect of grain boundaries in semiconductors [8].

The fundamental principle of $\mathrm{BaTiO}_{3}$-based ceramics with PTCR was summarized by Heywang $[13,33]$. Later,

\footnotetext{
* Corresponding author. Tel.: +86-411-87429934; fax: +86-41187429934. E-mail address: shirlyllei@dlmu.edu.cn (Z. Zhai)
}

the knowledge was extended by Jonker [34] and Daniels [35]. However, the understanding of $\mathrm{BaTiO}_{3}$-based ceramics was still insufficient because of the complexity of the system. In recent decades, the technique of reducing sintering was introduced to protect the electrodes of laminated ceramics [36]. In the reducing atmosphere, the ceramic characteristics revealed great differences from the ones sintered in air [37, 38]. Also, the donor dopant density was much higher than before [39]. Therefore, it is necessary to revisit some basic questions in the $\mathrm{BaTiO}_{3}$ based ceramics for PTCR thermistors.

In the present work, the highly donor-doped ceramics with composition of $\mathrm{Ba}_{0.984} \mathrm{Y}_{0.016} \mathrm{TiO}_{3}$ are prepared via a solid reaction route for PTCR thermistors, which are sintered in the reducing atmosphere and oxidized in air. The effects of $\mathrm{Mn}$ additive on the properties of the prepared ceramics are investigated in the aspects of composition and morphology. Electrical characterizations of room temperature resistivity, PTCR jump, effective donor and acceptor density as well as depletion layer width are also conducted.

\section{MATERIALS AND METHODS}

Analytical reagents of $\mathrm{BaCO}_{3}, \mathrm{Y}_{2} \mathrm{O}_{3}$ and $\mathrm{TiO}_{2}$ were weighed and mixed according to the composition of $\mathrm{Ba}_{0.984} \mathrm{Y}_{0.016} \mathrm{TiO}_{3}$ by ball-milling for $5 \mathrm{~h}$. The ball-milling process was conducted by $\mathrm{ZrO}_{2}$ balls with the same weight of powder and deionized water. The mixture was dried and calcined in aerial atmosphere at $1100{ }^{\circ} \mathrm{C}$ for $2 \mathrm{~h}$. After the calcination, the sintering aids of boron nitride $(\mathrm{BN})$ and $\mathrm{BaO}$ [10] were added into the resultant with the amount of $5 \%$ and $2.5 \%$, respectively. Then, $\mathrm{Mn}\left(\mathrm{NO}_{3}\right)_{2}$ addition was incorporated with $\mathrm{Mn} / \mathrm{Ti}$ ratio of $0,0.0005,0.0010,0.0015$ and 0.0020 . The composite was continuously ball-milled for $5 \mathrm{~h}$ for the final powder, which followed the formula of $\mathrm{Ba}_{0.984} \mathrm{Y}_{0.016} \mathrm{TiO}_{3}+0.025 \mathrm{BaO}+0.05 \mathrm{BN}+\mathrm{xMn}\left(\mathrm{NO}_{3}\right)_{2}$, ( $\mathrm{x}=0 / 0.0005 / 0.0010 / 0.0015 / 0.0020)$. 
The tape-casting technique was employed to prepare the green ceramics. The powder was commingled with organics of tributyl phosphate, ethanol, chlorylene, dibutylphthalate, polyvinyl butyral by ball-milling for $6 \mathrm{~h}$. The weight ratio of powder to organics was 1:1.56. The acquired slurry was stood for $12 \mathrm{~h}$ before it was poured on a steel substrate to pass under a doctor blade. Then, a sheet with thickness of $1 \mathrm{~mm}$ was obtained and dried for $12 \mathrm{~h}$. It was cut into pieces for green ceramics, the dimensions of which were $10 \mathrm{~mm} \times 10 \mathrm{~mm} \times 1 \mathrm{~mm}$. The green ceramics were sintered in a reducing atmosphere of $97 \% \mathrm{~N}_{2}+3 \% \mathrm{H}_{2}$. The sintering was conducted at the temperatures of $340{ }^{\circ} \mathrm{C}$ for $1 \mathrm{~h}, 1150{ }^{\circ} \mathrm{C}$ for $10 \mathrm{~min}$ and $950{ }^{\circ} \mathrm{C}$ for $2 \mathrm{~h}$, in order to control the grain growth of the ceramics [12]. The heating and cooling rates were 300 and $200{ }^{\circ} \mathrm{C} / \mathrm{h}$, respectively. The obtained ceramics were oxidized in the aerial atmosphere at $650-850{ }^{\circ} \mathrm{C}$.

The In-Ga alloy electrodes were pasted on both sides of the ceramics for electrical characterizations. The resistivity-temperature (R-T) property was collected by a computer-controlled R-T analyzer in the temperature range of $25-250{ }^{\circ} \mathrm{C}$. The PTCR jump was defined as the logarithmic ratio of ceramic resistivity at $250{ }^{\circ} \mathrm{C}\left(\rho_{250}\right)$ to the one at $25{ }^{\circ} \mathrm{C}\left(\rho_{25}\right)$. The X-ray diffraction (XRD) and scanning electron microscopy (SEM) were conducted by Rigaku D/MAX-Ultima and Philips XL-30TMP for the characterizations of composition and morphology. The scan speed of XRD was $0.5 \%$ min.

\section{RESULTS AND DISCUSSION}

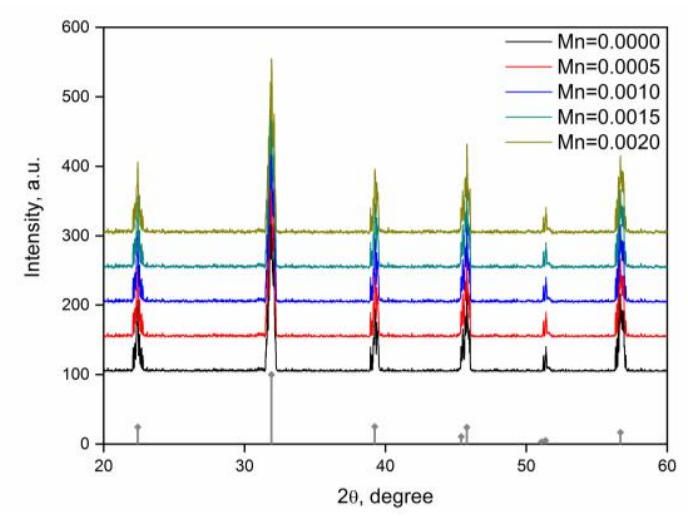

Fig. 1. X-ray diffraction patterns of $\mathrm{Ba}_{0.984} \mathrm{Y}_{0.016} \mathrm{TiO}_{3}$ ceramics with $\mathrm{Mn}$ additives of $0-0.0020$ and the standard pattern of $\mathrm{BaTiO}_{3}$ material

0 shows the XRD patterns of $\mathrm{Ba}_{0.984} \mathrm{Y}_{0.016} \mathrm{TiO}_{3}$ ceramics with various $\mathrm{Mn}$ additive amounts. The peaks are in agreements with the standard pattern from JCPDS 01-089-1428, confirming the tetragonal $\mathrm{BaTiO}_{3}$ lattice system. The effect of $\mathrm{Mn}$ additive on the lattice structure is not detectable. The Mn-containing composites usually appear on the surface of grain as tiny acceptors, which are indiscernible in XRD analysis. Thus, there is no evidence to show the influence of Mn additive on lattice structure of the present ceramics. Furthermore, it is also concluded that Y dopant make little changes on the XRD patterns [28]. The crystallite size of the ceramics is about $30.4 \mathrm{~nm}$, which is calculated based on the (101) peak from the Scherrer formula. It infers that the crystallite size remains almost the same whatever the Mn additive amount is used.

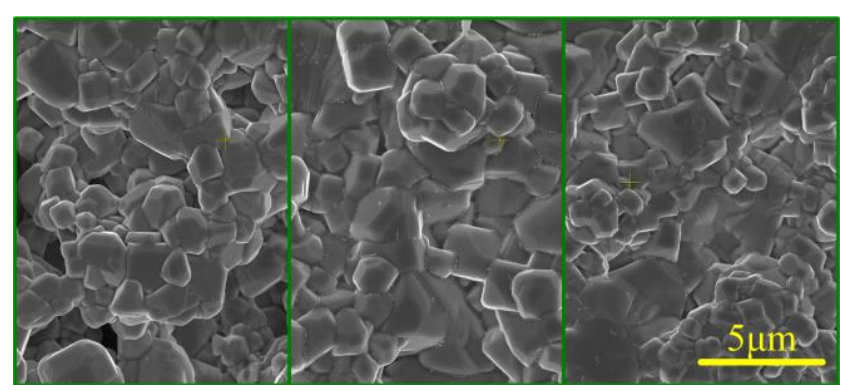

a

b

c

Fig. 2. Morphologies of $\mathrm{Ba}_{0.984} \mathrm{Y}_{0.016} \mathrm{TiO}_{3}$ ceramics with various Mn additive amounts: $\mathrm{a}$-for 0 ; $\mathrm{b}$-for 0.0005 ; $\mathrm{c}$-for 0.0010

The ceramic morphologies of the prepared samples with $\mathrm{Mn}$ additive amounts of $0,0.0005$ and 0.0010 are shown in 0 . The average grain sizes are 1.16, 1.65 and $1.01 \mu \mathrm{m}$, respectively. The ceramic without $\mathrm{Mn}$ additive appears to be porous, as shown in 0 a. The incorporation of Mn element leads to the growth of grains, which are compacted without any porous, as $0 \mathrm{~b}$. However, the continuous addition of $\mathrm{Mn}$ species inhibits the grain growth and the number of grain boundaries increases, as $0 \mathrm{c}$. The effect of $\mathrm{Mn}$ additive on the ceramic structure would influence the electrical properties of the ceramics. It is noted that there would be some differences in microstructure if polished ceramics are used. The effect of $\mathrm{Mn}$ additive on grain growth would be of complexity. It is found that the heavy Mn doping $(1.5-1.8 \%)$ may cause a drastic change in the microstructure of ceramics, from tetragonal to hexagonal system. The acceptors of manganese interact with the oxygen vacancies by combining to a complex [40]. Both of these would be the reasons for the effect of Mn additive on grain size. However, it is still expected for further investigations of the present ceramics with slight $\mathrm{Mn}$ doping.

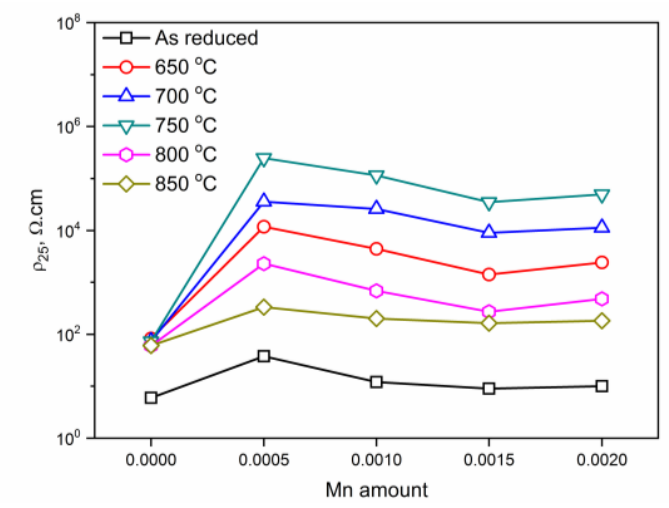

Fig. 3. Effect of Mn additive amount on room temperature resistivities of $\mathrm{Ba}_{0.984} \mathrm{Y}_{0.016} \mathrm{TiO}_{3}$ ceramics as reduced and oxidized at $650-850^{\circ} \mathrm{C}$

0 illustrates the effect of $\mathrm{Mn}$ additive amount on room temperature resistivity of the ceramics as reduced and oxidized at $650-850{ }^{\circ} \mathrm{C}$. Compared to the ceramics without $\mathrm{Mn}$ addition, the resistivities of $\mathrm{Mn}$-doped ceramics increase because the Mn element usually acts as 
the acceptors on grain surface. However, the resistivities reach the peak at $\mathrm{Mn}$ additive amount of 0.0005 and further incorporation of $\mathrm{Mn}$ dopant leads to a decrease of resistivity. The ceramic resistivity is also dependent on the temperature of oxidization. The dependence has been interpreted in the previous work, which proposed the establishment of spontaneous polarization at grain boundaries when high oxidizing temperature was used [10].

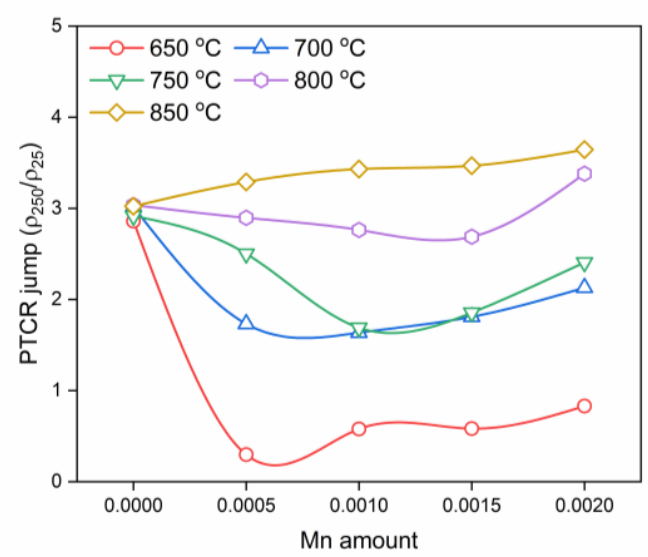

Fig. 4. Temperature dependence of the reduced resistivity $\left(\rho_{r d}\right)$ of Ba0.984 $\mathrm{Y}_{0.016} \mathrm{TiO}_{3}$ ceramics with $\mathrm{Mn}$ additive amounts of $0-0.0020$

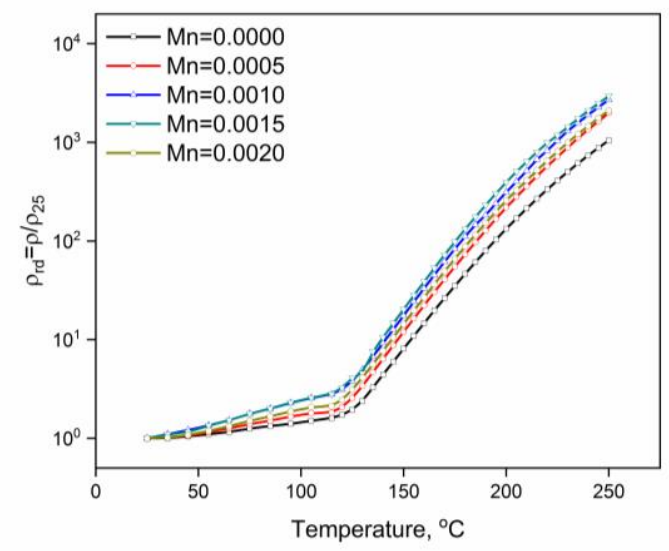

Fig. 5. Effect of Mn additive amount on PTCR jump of $\mathrm{Ba}_{0.984} \mathrm{Y}_{0.016} \mathrm{TiO}_{3}$ ceramics, which were oxidized at $650-850{ }^{\circ} \mathrm{C}$

0 exhibits the temperature dependence of ceramics resistivity. The ceramics shows the PTCR effect with Curie point at $120{ }^{\circ} \mathrm{C}$, above which the dielectric constant decreases according to the Curie-Weiss law [13]. The Curie point (temperature) remains the same when $\mathrm{Mn}$ additive amount is from 0 to 0.0020 . For convenience in discussion, the reduced resistivity $\left(\rho_{r d}\right)$ is introduced and it is equal to the ratio of ceramic resistivity at a temperature to the room temperature resistivity. The effect of $\mathrm{Mn}$ additive amount on PTCR jump of the ceramics oxidized at $650-850{ }^{\circ} \mathrm{C}$ is revealed in 0 . The relationship between $\mathrm{Mn}$ additive amount and PTCR jump is influenced by the temperature of oxidization. At low oxidization temperature, the PTCR jump is inhibited by the Mn additive even though it shows a slight increase with the Mn-doping amount. On the other hand, the PTCR jump increases in a monotonous way if high oxidization temperature of $850{ }^{\circ} \mathrm{C}$ is used.

The acceptor-state density and depletion layer width are key factors that influence the electrical properties on the ceramics. It is necessary to put an attempt to evaluate the values of both parameters. As the commonly accepted operation, the ceramic resistivity $(\rho)$ can be expressed as Eq. $1[13,28,41]$.

$\rho=\rho_{0} \exp \left(\frac{q^{2} N_{S}^{2}}{2 \varepsilon_{0} \varepsilon_{r} k T N_{d}}\right)$,

where, $\rho_{0}$ is the flat-band resistivity and it equals to $1 / q \mu N_{d}$ if the donors are assumed to be first-order ionized. $q, k$ and $\mu$ are the elementary charge, Boltzmann constant and carrier mobility. $N_{d}$ and $N_{S}$ are the densities of ionized donors in the grain and acceptor states on the grain surface. $\varepsilon_{0}$ is the vacuum permittivity and $\varepsilon_{r}$ is the relative permittivity of ceramics. $T$ is the operating temperature. It is known that $\varepsilon_{r}$ follows the Curie-Weiss law when the operating temperature is above the Curie point, as shown in Eq. 2.

$$
\varepsilon_{r}=\frac{C}{T-\theta},
$$

were, $C$ is the Curie constant equal to $1.5 \times 10^{5} \mathrm{~K}$ and $\theta$ is the extrapolate Curie-Weiss temperature of $383 \mathrm{~K}$ [13]. Thus, the reduced resistivity $\left(\rho_{r d}\right)$ could be formulated as Eq. 3, which has a logarithmic form of Eq. 4.

$$
\begin{aligned}
& \rho_{r d}=\frac{\rho_{0}}{\rho_{25}} \exp \left[\frac{q^{2} N_{S}^{2}}{2 \varepsilon_{0} k C N_{d}}\left(1-\frac{\theta}{T}\right)\right] ; \\
& \ln \rho_{r d}=\ln \rho_{0}-\ln \rho_{25}+\frac{q^{2} N_{S}^{2}}{2 \varepsilon_{0} k C N_{d}}\left(1-\frac{\theta}{T}\right) .
\end{aligned}
$$

Then, $\ln \rho_{r d}$ is of linear relationship with $T^{-1}$ and the slope $(S)$ could be expressed as Eq. 5. Therefore, $N_{S}$ could be evaluated provided that $N_{d}$ is known.

$S=-\frac{d \ln \rho_{r d}}{d T^{-1}}=\frac{q^{2} \theta N_{S}^{2}}{2 \varepsilon_{0} k C N_{d}}$.

The $N_{d}$ is evaluated based on the resistivity of ceramics as reduced, in which the acceptor states at grain boundaries are compensated by the large amount of oxygen vacancies. In this case, an approximation is made that the ceramic resistivity is equal to flat-band resistivity. Therefore, $N_{d}$ is calculated by $N_{d}=1 / \rho q \mu$.

0 plots the temperature dependent resistivity of ceramics with various $\mathrm{Mn}$ additive amounts in the coordinates of $\ln \rho_{r d}$ against $T^{-1}$. The slope for each sample is evaluated in order to calculate the values of $N_{S}$, which are shown in 0 . The presence of $\mathrm{Mn}$ additive decreases the effective acceptor-state density on the grain surface. The ceramic with $\mathrm{Mn}$ additive amount of 0.0005 has the least $N_{S}$ value of $1.19 \times 10^{17} \mathrm{~m}^{-3}$. The subsequent $\mathrm{Mn}$ incorporation enhances the effective acceptor-state density, which is still lower than the ceramic without Mn addition. 
According to the Schottky barrier model, the depletion layer width $(w)$ can be calculated based on $N_{d}$ and $N_{S}$, by $w=N_{S} / N_{d}$. The results of $w$ are also plotted in 0 , as the relationship between $w$ and Mn additive amount. The depletion layer width is $138 \mathrm{~nm}$ for the ceramic without $\mathrm{Mn}$ addition and it is expanded by the $\mathrm{Mn}$ addition, ranging from $358 \mathrm{~nm}$ to $176 \mathrm{~nm}$. It is noted that the present evaluation of depletion layer width is completed when $\varepsilon_{r}$ follows the Curie-Weiss law. However, Mn addition could also make possible impacts on $\varepsilon_{r}$ and the influence is not taken into consideration. The approximation had to be made not only for the convinience in calculation but also because the detail impacts of $\mathrm{Mn}$ addition on $\varepsilon_{r}$ has not been formulated yet. It would bring inaccuracy to the results and further modifications are expected once the quantitative studies of $\mathrm{Mn}$ addition on $\varepsilon_{r}$ are available.

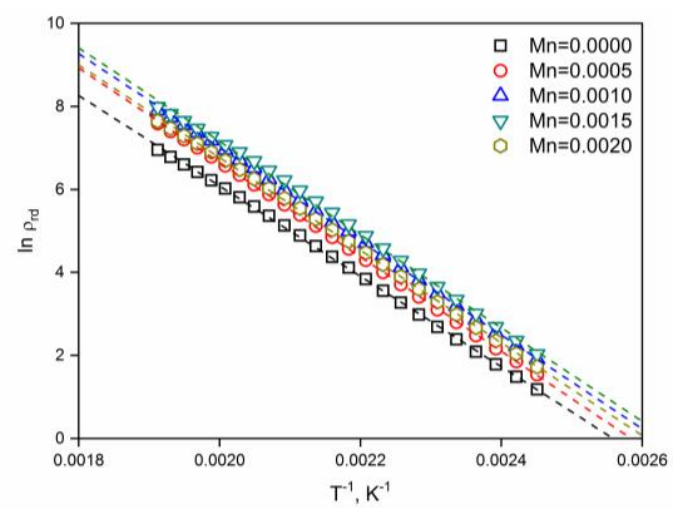

Fig. 6. Correlations of $\ln \rho_{r d}$ against $T^{-1}$ for the $\mathrm{Ba}_{0.984} \mathrm{Y}_{0.016} \mathrm{TiO}_{3}$ ceramics with $\mathrm{Mn}$ additive amount of $0-0.0020$

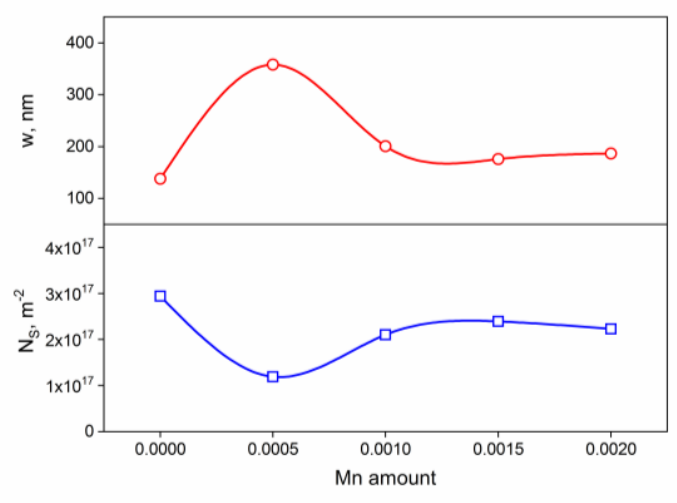

Fig. 7. Effect of Mn additive amount on the depletion layer width (w) and acceptor-state density $\left(N_{S}\right)$ of the Ba0.984 $\mathrm{Y}_{0.016} \mathrm{TiO}_{3}$ ceramics with $\mathrm{Mn}$ additive amount of $0-0.0020$

0 illustrates the summary of characteristics of $\mathrm{Ba}_{0.984} \mathrm{Y}_{0.016} \mathrm{TiO}_{3}$ ceramics oxidized at $850{ }^{\circ} \mathrm{C}$ in order to reveal the effect of $\mathrm{Mn}$ additive. As shown in 0 , the $\mathrm{Mn}$ incorporation results in the change of grain morphology. The ceramic is in compacted structure and the anomaly growth of grains reduces the number of grain boundaries. It is known that the acceptor states on grain surface comprise of the adsorbed oxygen and Mn species. The compacted grain interaction leaves little space for the adsorbed oxygen, leading to the decrease of $N_{S}$, even though the $\mathrm{Mn}$ is added as the acceptor. However, the Mn atoms may be incorporated into the grain bulks, compensating the donors. Thus, the effective donor density $\left(N_{d}\right)$ decreases together with the room temperature conductance. The depletion layer changes its width accordingly because it is determined by the values of $N_{S}$ and $N_{d}$. For the PTCR jump, it decreases because of the compacted grain structure after $\mathrm{Mn}$ incorporation to the ceramic oxidized at $650{ }^{\circ} \mathrm{C}$, which is a low temperature for grain boundary oxidization. On the other hand, when the oxidation temperature is lifted to $850{ }^{\circ} \mathrm{C}$, the aerial oxygen is able to diffuse through the grain boundaries, providing an enhancement in PTCR effect of the ceramics. Nevertheless, the mechanism of $\mathrm{Mn}$ additive in the $\mathrm{BaTiO}_{3}$-based ceramics is still complex and further investigations are expected.

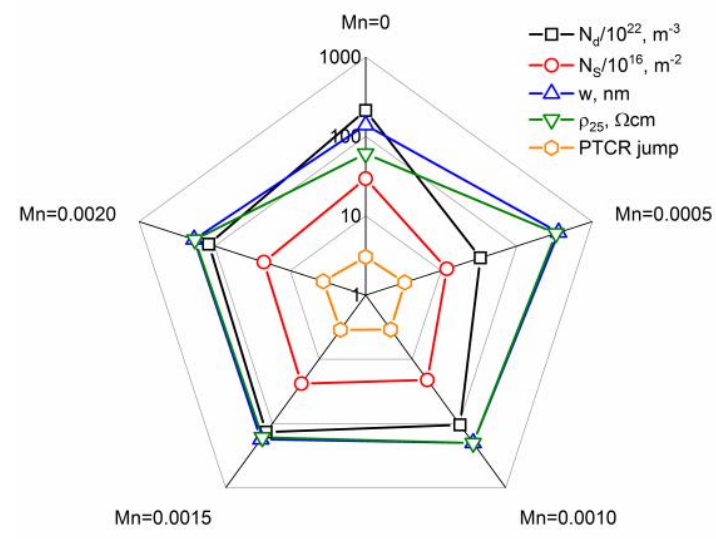

Fig. 8. Characteristics of $\mathrm{Ba}_{0.984} \mathrm{Y}_{0.016} \mathrm{TiO}_{3}$ ceramics with $\mathrm{Mn}$ additive amount of $0-0.0020$ oxidized at $850{ }^{\circ} \mathrm{C}$

It is necessary to compare the present ceramic properties with the published reports, which used similar composition and preparation techniques. In the present work, the highest PTCR jump of 3.64 appears in the ceramics with Mn additive amount of 0.0020 , which has a room temperature resistivity of $182 \Omega \mathrm{cm}$ and depletion layer width of $186 \mathrm{~nm}$. Compared to the $\mathrm{BaTiO}_{3}$-based ceramic prepared by sol-gel technique [28], the present sample has a less room temperature resistivity even though acceptor additive is incorporated. C. Gao prepared the ceramic from hydrothermal $\mathrm{BaTiO}_{3}$ nanocrystalline powder with the $\mathrm{Mn}$ additive of 0.0005 . It has a room temperature resistivity of $136 \Omega \mathrm{cm}$ and a depletion layer width of $80 \mathrm{~nm}$ [12]. Both of the values are less than the present ceramic with the same Mn amount. However, the equivalent PTCR jumps are observed from the comparison between the present ceramic and C. Gao's samples.

\section{CONCLUSIONS}

The highly donor-doped ceramics of $\mathrm{Ba}_{0.984} \mathrm{Y}_{0.016} \mathrm{TiO}_{3}$ are prepared for PTCR thermistors. The Mn incorporation makes little impact on ceramic composition but leads to an obvious change in ceramic morphology, which reveals the average grain size of $1.16,1.65$ and $1.01 \mu \mathrm{m}$ for $\mathrm{Mn}$ additive amounts of $0,0.0005$ and 0.0010 , respectively. The room temperature resistivity and the donor density are dependent on the amount of $\mathrm{Mn}$ dopant, which may compensate the donors in the grain. As one of the acceptor species, Mn not only locates itself on the grain surface but also decreases the amount of adsorbed oxygen by 
stimulating the grain growth. The $N_{S}$ and $w$ for the ceramic with $\mathrm{Mn}$ addition amount of 0.0005 are evaluated to be $1.19 \times 10^{17} \mathrm{~m}^{-3}$ and $358 \mathrm{~nm}$. At low oxidization temperature, the PTCR jump is inhibited by the Mn additive even though it shows a slight increase with the Mn-doping amount. On the other hand, the PTCR jump increases in a monotonous way if high oxidization temperature of $850{ }^{\circ} \mathrm{C}$ is used.

\section{Acknowledgments}

This work is financially supported by the National Natural Science Foundation of China (Grant No. 11704055), the Liaoning Natural Science Foundation (Grant No. 20180510021), the Dalian High-level Talents Innovation Supporting Program (Grant No. 2017RQ073) and the Fundamental Research Funds for the Central Universities (Grant No. 3132019212, 3132019348).

\section{REFERENCES}

1. Shen, Z., Chen, W., Qi, J., Wang, Y., Chan, H., Chen, Y., Jiang, X. Dielectric Properties of Barium Titanate Ceramics Modified by $\mathrm{Sio}_{2}$ and by $\mathrm{Bao}^{-\mathrm{SiO}_{2}}$ Physica $\mathrm{B}$ : Condensed Matter 404 (16) 2009: pp. 2374-2376. https://doi.org/10.1016/j.physb.2009.04.039

2. Wang, S.F., Yang, T.C., Wang, Y.R., Kuromitsu, Y. Effect of Glass Composition on the Densification and Dielectric Properties of Batio3 Ceramics Ceramics International 27 (2) 2001: pp. 157-162. https://doi.org/10.1016/s0272-8842(00)00055-9

3. Zhao, C., Wu, B., Thong, H.C., Wu, J. Improved Temperature Stability and High Piezoelectricity in LeadFree Barium Titanate-Based Ceramics Journal of the European Ceramic Society 38 (16) 2018: pp. 5411-5419. https://doi.org/10.1016/j.jeurceramsoc.2018.08.004

4. Marino, A., Almici, E., Migliorin, S., Tapeinos, C., Battaglini, M., Cappello, V., Marchetti, M., de Vito, G., Cicchi, R., Pavone, F.S., Ciofani, G. Piezoelectric Barium Titanate Nanostimulators for the Treatment of Glioblastoma Multiforme Journal of Colloid and Interface Science 538 2019: pp. $449-461$. https://doi.org/10.1016/j.jcis.2018.12.014

5. Li, F., Zhou, M., Zhai, J., Shen, B., Zeng, H. Novel Barium Titanate Based Ferroelectric Relaxor Ceramics with Superior Charge-Discharge Performance Journal of the European Ceramic Society 38 (14) 2018: pp. 4646-4652. https://doi.org/10.1016/j.jeurceramsoc.2018.06.038

6. Fang, C., Liu, W.H. A Theoretical Investigation of the Influence of the Surface Effect on the Ferroelectric Property of Strained Barium Titanate Film Physica B: Condensed Matter 517 2017: pp. 35-41.

https://doi.org/10.1016/j.physb.2017.05.009

7. Reynolds, A.J., Conboy, J.C. Barium Titanate Nanoparticle Based Nonlinear Optical Humidity Sensor Sensors and Actuators B: Chemical 273 2018: pp. 921-926. https://doi.org/10.1016/j.snb.2018.07.004

8. Goodman, G. Electrical Conduction Anomaly in SamariumDoped Barium Titanate Journal of the American Ceramic Society 46 (1) 1963: pp. $48-54$. https://doi.org/10.1111/j.1151-2916.1963.tb13770.x

9. Zubair, M.A., Leach, C. Modeling the ResistanceTemperature Characteristic of a Positive Temperature Coefficient Thermistor, Using Experimentally Determined
Permittivity Data Applied Physics Letters

2007: pp. 484.

https://doi.org/10.1063/1.2768034

10. Liu, J., Gong, S., Quan, L., Chen, B., Zhou, D. Reoxidation Effects of Ba-Excessive Barium Titanate Ceramics for Laminated Positive Temperature Coefficient Thermistors Journal of the American Ceramic Society 95 (5) 2012: pp. 1640-1644. https://doi.org/10.1111/j.1551-2916.2011.05041.x

11. Liu, J., Gong, S., Jin, G., Zhai, Z., Zhao, Y., Luo, C., Jiang, Q. Influence of Reoxidation on Silica-Containing Barium Titanate Ceramics for Ptcr Thermistors Prepared by Tape Casting Ceramics-Silikáty 60 (1) 2016: pp. 58-62. https://doi.org/10.13168/cs.2016.0008

12. Gao, C., Fu, Q., Zhou, D., Zu, H., Chen, T., Xue, F., Hu, Y., Zheng, Z., Luo, W. Nanocrystalline Semiconducting Donor-Doped Batio3 Ceramics for Laminated Ptc Thermistor Journal of the European Ceramic Society 37 (4) 2017: pp. 1523-1528. https://doi.org/10.1016/j.jeurceramsoc.2016.11.001

13. Heywang, W. Resistivity Anomaly in Doped Barium Titanate Journal of the American Ceramic Society 47 (10) 1964: pp. $484-490$. https://doi.org/10.1111/j.1151-2916.1964.tb13795.x

14. Makovec, D., Ule, N., Drofenik, M. Positive Temperature Coefficient of Resistivity Effect in Highly Donor-Doped Barium Titanate Journal of the American Ceramic Society 84 (6) 2010: pp. $1273-1280$.

https://doi.org/10.1111/j.1151-2916.2001.tb00828.x

15. Langhammer, H.T., Makovec, D., Pu, Y., Abicht, H.P., Drofenik, M. Grain Boundary Reoxidation of Donor-Doped Barium Titanate Ceramics Journal of the European Ceramic Society 26 (14) 2006: pp. 2899-2907. https://doi.org/10.1016/j.jeurceramsoc.2006.02.006

16. Huybrechts, B., Ishizaki, K., Takata, M. Experimental Evaluation of the Acceptor-States Compensation in PositiveTemperature-Coefficient-Type Barium Titanate Journal of the American Ceramic Society 75 (3) 1992: pp. $722-724$. https://doi.org/10.1111/j.1151-2916.1992.tb07867.x

17. Ho, I.C. Semiconducting Barium Titanate Ceramics Prepared by Boron-Containing Liquid-Phase Sintering Journal of the American Ceramic Society $77(3)$ 1994: pp. 829-832. https://doi.org/10.1111/j.1151-2916.1994.tb05372.x

18. Itzke, D.V., Abicht, H.P. The Influence of Different Additives and the Mode of Their Addition on the Sintering Behavior and the Properties of Semiconducting Barium Titanate Ceramics Solid State Sciences 2(1) 2000: pp. $149-159$. https://doi.org/10.1016/S1293-2558(00)00128-X

19. Felgner, K.H., $\quad$ Müller, T., Langhammer, H.T., Abicht, H.P. Investigations on the Liquid Phase in Barium Titanate Ceramics with Silica Additives Journal of the European Ceramic Society 21 (10) 2001: pp. 1657-1660. https://doi.org/10.1016/s0955-2219(01)00086-3

20. Lee, Y.C., Lin, C.W., Lu, W.H., Chen, W.J., Lee, W.H. Influence of $\mathrm{Sio}_{2}$ Addition on the Dielectric Properties and Microstructure of (Ba0. 96ca0. 04)(Ti0. 85zro. 15)O 3 Ceramics International Journal of Applied Ceramic Technology 6 (6) 2009: pp. $692-701$ https://doi.org/10.1111/j.1744-7402.2009.02379.x

21. Kim, J.G., Cho, W.S., Park, K. Ptcr Characteristics in Porous (Ba,Sr) Tios Ceramics Produced by Adding Partially Oxidized Ti Powders Materials Science and Engineering $B$ 77 (3) 2000: pp. $255-260$. 
https://doi.org/10.1016/s0921-5107(00)00496-7

22. He, Z., Ma, J., Qu, Y., Feng, X. Effect of Additives on the Electrical Properties of a (Ba0.92Sr $\left.\mathrm{Sr}_{0.08}\right)$ Tioz-Based Positive Temperature Coefficient Resistor Journal of the European Ceramic Society 22 (13) 2002: pp. 2143-2148. https://doi.org/10.1016/s0955-2219(01)00538-6

23. Kim, J.G., Cho, W.S., Park, K. Effect of Reoxidation on the Ptcr Characteristics of Porous (Ba,Sr)Tio 3 Materials Science and Engineering B 94 (2-3) 2002: pp. 149-154. https://doi.org/10.1016/s0921-5107(01)00946-1

24. Jo, S.K., Han, Y.H. Effects of Reoxidation Process on Positive Temperature Coefficient of Resistance Properties of Sm-Doped $\mathrm{Ba}_{0.85} \mathrm{Ca}_{0.15} \mathrm{tio}_{3}$ Japanese Journal of Applied Physics 46 (3A) 2007: pp. 1076. https://doi.org/10.1143/JJAP.46.1076

25. V'yunov, O.I., Kovalenko, L.L., Belous, A.G., Belyakov, V.N. Oxidation of Reduced Y-Doped Semiconducting Barium Titanate Ceramics Inorganic Materials 41 (1) 2005: pp. 87-93. https://doi.org/10.1007/s10789-005-0097-x

26. Park, K., Kim, J.G., Lee, K.J., Cho, W.S., Hwang, W.S. Electrical Properties and Microstructure of Y-Doped Batio3 Ceramics Prepared by High-Energy Ball-Milling Ceramics International 34 (7) 2008: pp. 1573-1577. https://doi.org/10.1016/j.ceramint.2006.04.007

27. Abicht, H.P., $\quad$ Langhammer, H., Felgner, K.H. The Influence of Silicon on Microstructure and Electrical Properties of La-Doped Bation Ceramics Journal of Materials Science 26 (9) 1991: pp. 2337-2342. https://doi.org/10.1007/bf01130178

28. Liu, J., Jin, G., Chen, Y., Xue, W. Properties of YttriumDoped Barium Titanate Ceramics with Positive Temperature Coefficient of Resistivity and a Novel Method to Evaluate the Depletion Layer Width Ceramics International 45 (5) 2019: pp. $6119-6124$.

https://doi.org/10.1016/j.ceramint.2018.12.086

29. Zubair, M., Leach, C. The Influence of Cooling Rate and $\mathrm{Sio}_{2}$ Additions on the Grain Boundary Structure of MnDoped Ptc Thermistors Journal of the European Ceramic Society 28 (9) 2008: pp. 1845-1855. https://doi.org/10.1016/j.jeurceramsoc.2007.12.034

30. Niimi, H., Ishikawa, T., Mihara, K., $\quad$ Sakabe, Y., Kuwabara, M. Effects of $\mathrm{Ba} / \mathrm{Ti}$ Ratio on Positive Temperature Coefficient of Resistivity Characteristics of Donor-Doped Batio3 Fired in Reducing Atmosphere Japanese Journal of Applied Physics $46(2)$ 2007: pp. $675-680$. https://doi.org/10.1143/JJAP.46.675

31. Niimi, H., Mihara, K., Sakabe, Y., Kuwabara, M. Influence of $\mathrm{Ba} / \mathrm{Ti}$ Ratio on the Positive Temperature Coefficient of Resistivity Characteristics of Ca-Doped
Semiconducting Batio3 Fired in Reducing Atmosphere and Reoxidized in Air Journal of the American Ceramic Society 90 (6) 2007: pp. 1817-1821. https://doi.org/10.1111/j.1551-2916.2007.01701.x

32. Kolodiazhnyi, T., Petric, A. Effect of $\mathrm{P}_{\mathrm{o} 2}$ on Bulk and Grain Boundary Resistance of N-Type Batioz at Cryogenic Temperatures Journal of the American Ceramic Society 86 (9) 2003: pp. $1554-1559$. https://doi.org/10.1111/j.1151-2916.2003.tb03513.x

33. Heywang, W. Semiconducting Barium Titanate Journal of Materials Science 6(9) 1971: pp. 1214-1224. https://doi.org/10.1007/bf00550094

34. Jonker, G.H. Some Aspects of Semiconducting Barium Titanate Solid-State Electronics 7 (12) 1964: pp. 895-903. https://doi.org/10.1016/0038-1101(64)90068-1

35. Daniels, J., Hardtl, K.H., Hennings, D., Wernicke, R. Defect Chemistry and Electrical Conductivity of Doped Barium Titanate Ceramics Philips Research Reports 31 (6) 1976: pp. $487-560$.

36. Zu, H., Fu, Q., Gao, C., Chen, T., Zhou, D., Hu, Y., Zheng, Z., Luo, W. Effects of $\mathrm{BacO}_{3}$ Addition on the Microstructure and Electrical Properties of La-Doped Barium Titanate Ceramics Prepared by ReductionReoxidation Method Journal of the European Ceramic Society 38 (1) 2018: pp. 113-118. https://doi.org/10.1016/j.jeurceramsoc.2017.07.022

37. Zu, H., Chen, T., Gao, C., Fu, Q., Zhou, D., Hu, Y., Zheng, Z., Luo, W. Abnormal Reoxidation Effects in BaExcess La-Doped Batio3 Ceramics Prepared by the Reduction-Reoxidation Method Journal of the American Ceramic Society 100 (7) 2017: pp. 2958-2964. https://doi.org/10.1111/jace.14823

38. Zhou, D., Zhao, D., Fu, Q., Hu, Y., Jian, G., Cheng, X., Shen, X. Particle Sizes Effects on Electrical Properties and Densification of Laminated $\mathrm{Ba}_{1.002} \mathrm{la}_{0.003} \mathrm{tio}_{3}$ Ceramics Ceramics International 39 (3) 2013: pp. 2457-2462. https://doi.org/10.1016/j.ceramint.2012.08.098

39. Liu, J., Gong, S., Quan, L. Effects of $\mathrm{Sio}_{2}$ Addition on Ba Excessive Barium Titanate Ceramics Sintered in Reducing Atmosphere for Laminated Ptcr Thermistors Materials Research Innovations 18 (S2) 2014: pp. 172-176. https://doi.org/10.1179/1432891714Z.000000000395

40. Langhammer, H.T., Müller, T., Polity, A., Felgner, K.H., Abicht, H.P. On the Crystal and Defect Structure of Manganese-Doped Barium Titanate Ceramics Materials Letters $26(4)$ 1996: pp. 205-210. https://doi.org/10.1016/0167-577X(95)00230-8

41. Yamazoe, N., Shimanoe, K. Theory of Power Laws for Semiconductor Gas Sensors Sensors and Actuators B: Chemical 128 (2) 2008: pp. 566-573. https://doi.org/10.1016/j.snb.2007.07.036 